\title{
Fungus-Mediated synthesis of silver nanoparticles using Aspergillosis causing
} fungi

\author{
Mohamed B. Aboul-Nasr ${ }^{*}$, Sabah S. Mohamed ${ }^{2}$, Alaa A. Yasien ${ }^{3}$ \\ 1,2,3 Botany and Microbiology Department, Faculty of Science, Sohag University, Sohag, Egypt. \\ doi:
}

\section{Abstract}

Green synthesis of metal nanoparticles has gained great attention due to the need for safe, cost-effective and eco-friendly technologies for metal nanoparticles synthesis. Fungi have been represented as a novel field of study in nanotechnology. This study was focused on extra/intracellular synthesis of highly stable silver nanoparticles (SNPs) using aspergillosis causing fungi. Four strains of opportunistic fungi isolated from aspergillosis suspected patients at Assiut University Chest Department A. flavus KY609551, A. fumigatus MT994683, A. niger KY609552 and A. terreus MF852635 were kindly provided by Enas M. Amer, Faculty of Science of Assiut University tested for their ability to synthesize SNPs extra/intracellularly. Exposure of fungal cell filtrate to $1 \mathrm{mM}$ of aqueous $\mathrm{Ag}^{+}$ions resulted in reduction of the metal ions and formation of silver nanoparticles. Visual observation showed the ability of the three different fungi namely A. flavus KY609551, A. fumigatus MT994683 and A. terreus MF852635 to produce SNPs. However, A. niger KY609552 could not gave SNPs at $1 \mathrm{mM}$ of aqueous $\mathrm{Ag}^{+}$ions. The bioreduction of SNPs was monitored by ultraviolet-visible spectroscopy, and the SNPs obtained
KEYWORDS

Silver nanoparticles, opportunistic fungi,

A.flavus,

A.fumigatus,

A. niger,

A. terreus.

\section{CORRESPONDING}

\section{AUTHOR}

Mohamed B. Aboul-Nasr mbassamaboulnasr@yahoo.com were characterized by Fourier Transform Infrared Spectroscopy (FTIR) and X-ray diffraction. UVvisible spectra demonstrate a strong, quite narrow peak located between 435 and $450 \mathrm{~nm}$ was obtained in case of A. flavus KY609551 and A. terreus MF852635, respectively. Whereas a wide peak centering at $435 \mathrm{~nm}$ in case of A. fumigatus MT994683. To prepare the X-ray diffraction and FTIR for samples, a modified simple technique for extracting SNPs from aqueous solution using chloroform was used. It is the first time to be reported that used chloroform as an extract of SNPs from their aqueous solution, to facilitate FTIR and X-ray examination. X-ray diffraction confirmed the formation of metallic silver. FTIR spectroscopy analysis showed the presence of an amide group which appears to be responsible for biosynthesis and stability of nanoparticles for both A. flavus KY609551 and A. terreus MF852635.

\section{INTRODUCTION}

Nanotechnology is concerned with the design and composition of nanoparticles in the nanometer range of 1-100 nanometers and controlling their size and shape (Mansoori 2005). The application of nanoscale materials and structures is an emerging area of nanotechnology.
Metal nanoparticles have been used in many scientific fields, in which silver nanoparticles of interest due to their surface resonance properties of the plasmon, which make it unique (Stiufiuc et al. 2013) and its antimicrobial effect (Franci $\boldsymbol{e t}$ al. 2015). Silver nanoparticles are used in many fields such as chemical/biological sensors and biomedical 
materials (Evtugyn et al. 2014 \& Alon et al. 2014), cosmetics (Colvin et al. 1994).

The manufacture of nanoparticles has several reported methods for the synthesis of SNPs using chemical, physical, photochemical and biological routes. Each method has advantages and disadvantages with common problems being, costs, stability, particle sizes and size distribution (Aboul El-Nour et al. 2010). Among the existing methods, biological methods are the most required method for producing nanoparticles as they are safe, lowcost technique and eco-friendly. Biological methods depend on the use of natural reducing agents such as polysaccharides, biological organism such as plants extract (Shankar et al. 2003, Jha et al. 2009, Ahmad et al. 2011, Rao et al. 2014 \& Elumalai et al. 2014), fungi (Mukherjee et al. 2001, Sastry et al. 2003, Bansal et al. 2005, Vigneshwaran et al. 2006, Ingle et al. 2009 \& Verma et al. 2010), yeast (Kowshik et al. 2002, Jha et al. 2009, Arumugam and Berchmans 2011 \& Kalathil et al. 2013) and bacteria (Saifuddin et al. 2009, Nanda and Saravanan 2009 \& Sintubin et al. 2009) to synthesize material either intra- or extracellularly. Thus, to be potentially utilized as eco-friendly nano factories (Shankar et al. 2004, Mohanpuria et al. 2008).

The fungal systems or myconanofactories have been exploited for the synthesis of metal nanoparticles. A large number of fungal strains are capable to synthesize SNPs extra/intracellularly, among which Fusarium oxysporum (Mukherjee et al. 2001 \& Ahmad et al. 2003), Neurospora crassa (Ingle et al. 2009), Aspergillus fumigatus (Bhainsa and D'Souza 2006), Aspergillus niger (Gade et al. 2008), and Aspergillus clavatus (Verma et al. 2010) have been proven their ability to synthesize SNPs.
Fungi are much better compared to other microorganisms in many ways that they are easy to culture on a large scale by solid substrate fermentation, thus making a large amount of biomass available for processing; also, fungi can grow over the surface of inorganic substrate during culture. This leads to the metal being distributed in a more efficient way as a catalyst. Biosynthesis of nanoparticles of different elements is reported from both pathogenic and nonpathogenic fungi (Vigneshwaran et al. 2007). Therefore, the use of opportunistic fungi to produce nanoparticles because of having a high wall-binding capacity as well as intracellular mineral absorption capabilities, also produce large amount of enzymes per unit biomass.

The basis of the bio-synthesis process is the producing extra/intracellular biochemical compound that acts as a reducing agent and capping agent. The difference in the manufacturing mechanism between the extra/intracellular is related to the difference in biological factors used by the cell during the process. Where the fungal cell wall containing sugars play a role in the absorption and reduction of silver ions (Meyer 2008).

The extracellular secretions of reductive proteins are more and can be easily handled in downstream processing. And also, since the nanoparticles precipitated outside the cell is devoid of unnecessary cellular components, it can be directly used in various applications (Narayanan and Sakthivel 2010).

Therefore, it was of great significance to explore novel fungal strains for synthesizing SNPs based on the biodiversity specially aspergillosis causing fungi strains. 


\section{MATERIALS AND METHODS}

\section{Source of strains}

The fungal Strains A. flavus KY609551, A. fumigatus MT994683, A. niger KY609552 and A. terreus MF852635 were kindly provided by Enas Amer from suspected patients at Assiut university hospital (Enas et al. 2017).

\section{Biomass Preparation}

\section{II.1. Extra-cellular enzyme preparation}

A. flavus KY609551, A. fumigatus MT994683, A. niger KY609552 and A. terreus MF852635 were grown in 250-ml Erlenmeyer flasks containing 100 $\mathrm{ml}$ potato dextrose incubated at $37^{\circ} \mathrm{C}$. After 8 days, the mycelia mat was separated from media by filtration then extensively washed with sterile deionized water to remove any medium components from the biomass. Typically, $10 \mathrm{~g}$ of biomass (fresh weight) of each strain dependently was soaked in $100 \mathrm{ml}$ de-ionized water and incubation at $37^{\circ} \mathrm{C}$ on a rotary shaker $(120 \mathrm{rpm})$ for $72 \mathrm{hrs}$. to obtain extra-enzymes under dark conditions. The cell filtrates were obtained by filtration using sterile Whatman filter paper no.1. The separated mycelia were re-used for detecting the intracellular products' activity as will be explained by (Ahmad et al. 2003).

\section{II.2. Obtaining of the intracellular products using}

\section{Bransonic ${ }^{\circledR}$ ultrasonic bath sonicator}

The previously obtained mycelia of each strain were re-suspended $(1 \mathrm{~g} / 10 \mathrm{ml})$ in separate $250 \mathrm{ml}$ sterile flasks and were held in Bransonic ${ }^{\circledR}$ ultrasonic bath sonicator at $35^{\circ} \mathrm{C}$. After $1 \mathrm{hr}$, the flasks were removed, and then filtered using the sterile Whatman filter paper no.1 to obtain the intracellular products from each fungal strain (Aboul-Nasr et al. 2018).

\section{Biosynthesis of SNPs}

For extra and intra-cellular biosynthesis of SNPs, $100 \mathrm{ml}$ of cell filtrates derived from different fungal strains were mixed with $0.0169 \mathrm{~g}$ of $\mathrm{AgNO} 3$ $(1 \mathrm{mM})$ and incubated at $37^{\circ} \mathrm{C}$. A negative control (1 ml) contains a solution of $1 \mathrm{mM} \mathrm{AgNO3}$ was exposed to the same experimental conditions. Also, one $\mathrm{mL}$ of each fungal filtrate was held as a positive control for comparison. All solutions were kept in dark to avoid any photochemical reactions during the experiment (Ahmad et al. 2003 \& Balaji et al. 2009).

\section{Characterization of silver nanoparticles}

Silver nanoparticles were characterized using visual-observation of change in color, UV-Vis spectrophotometer (JENWAY 7315 UV-Visible Spectrophotometer from 300-600nm), XDL 3000 powder X-ray diffractometer and Further characterization involved Fourier Transform Infrared Spectroscopy (FTIR) analysis of the dried powder of SNPs, by scanning it in the range 450 $4000 \mathrm{~cm}^{-1}$ at a resolution of $4 \mathrm{~cm}^{-1}$ (Ahmad et al. 2003).

\section{RESULTS AND DISCUSSION}

The color change of extra-cellular filtrate was observed visually from light yellow to reddish after two hours in case of A. terreus MF852635 and from four to five hours for A. flavus KY609551 and A. fumigatus MT994683, respectively (Fig.1). The color intensity of the cell filtrate with $\mathrm{AgNO}_{3}$ was sustained even after $24 \mathrm{hrs}$. incubation, which indicated that the particles were well dispersed in the solution, and there was no obvious aggregation. Whereas, when the intra-cellular filtrate was challenged with silver nitrate, a color change was observed after $4 \mathrm{hrs}$. in case of A. terreus MF852635, while intra-cellular filtrates of A. flavus 
KY609551 and A. fumigatus MT994683 showed change in color after $6 \mathrm{hrs}$. However, there is no reduction of silver ions when the extra and intracellular filtrate was challenged with a concentration of $(1 \mathrm{mM})$ of silver nitrate in the case of A. niger KY609552. Birla et al. (2013) reported that the appearance of reddish color of fungal cell filtrate from light yellow due to excitation of surface plasmon after being challenged with silver ions resembles the formation of SNPs. Thus, color change of the solution clearly indicated the formation of SNPs. These results were consistent

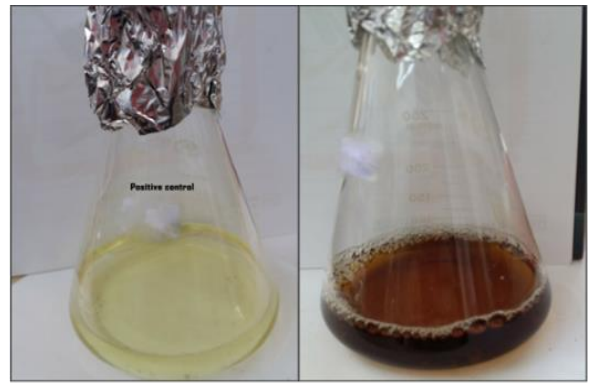

(a)

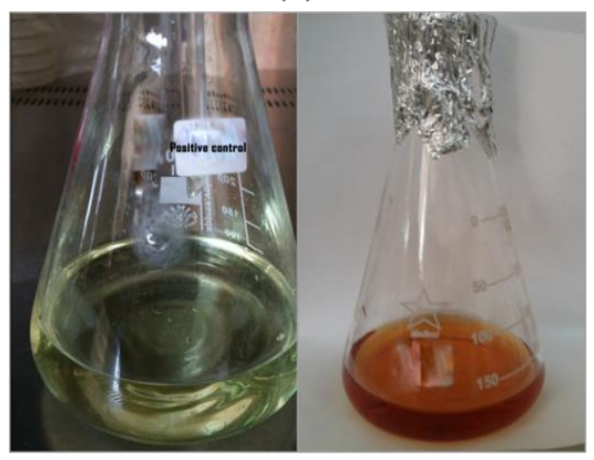

(c) with the report of Vigneshwaran et al. (2007), Jain et al. (2011), Li et al. (2012) and El Aziz et al. (2013), which indicates ability of A.terreus and A. flavus in induced SNPs at concentration $1 \mathrm{mM}$ of $\mathrm{AgNO}_{3}$. Bhainsa \& D'Souza (2006) reported that SNPs can be formed extra/intracellularly by using A. fumigatus. Sagar \& Ashok (2012) indicated the ability of $A$. niger to induce SNPs in a very high concentration of $\mathrm{Ag}^{+}$, whereas Gade et al. (2008) reported that $A$. niger could produce SNPs at $1 \mathrm{mM}$ of silver ions concentration.

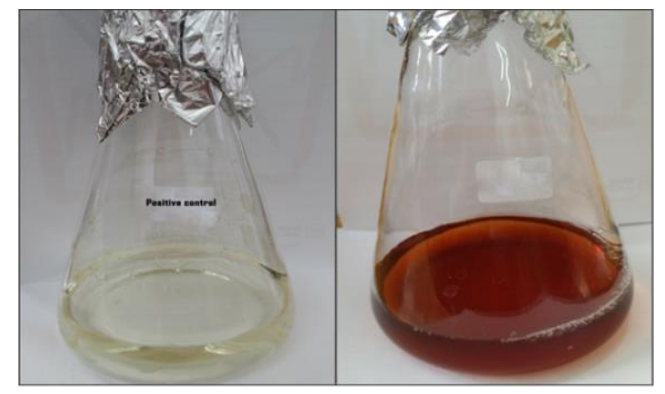

(b)

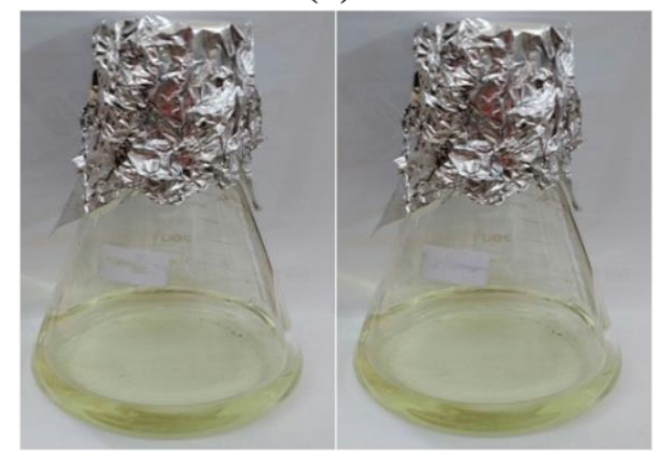

(d)

Figure 1: gradation in color four different fungal strains; a, b, c and d extra-enzyme filtrate in 24 hours after it was challenged with $1 \mathrm{mM}$ of silver ions from yellow to brown for A.terreus MF852635, A. flavus KY609551, A. fumigatus MT994683 and A. niger KY609552, respectively

\section{UV-Vis Spectrophotometers}

Silver nanoparticle production was monitored by the change in color (Fig. 1) showed the uv-visible spectra of the silver nitrate solutions challenged with the four fungal strains. While no absorption band was observed in both controls (positive and negative). A characteristic surface Plasmon absorption band at $450 \mathrm{~nm}$ was observed in $A$. terreus MF852635. While in case of A. flavus KY609551 and A. fumigatus MT994683 intensity peak was at $440 \mathrm{~nm}$ and $435 \mathrm{~nm}$, respectively in 24 hrs. which is characteristic surface plasmon resonance (SPR) peak of SNPs and hence confirmed their synthesis. After $72 \mathrm{hrs}$. of incubation, no change in intensity at $440 \mathrm{~nm}$ was observed indicating complete reduction of silver 
ions (Fig. 2). The UV-visible spectra of the silver nitrate solutions challenged with the four fungal strains intra-cellular cell filtrate. A. terreus MF852635 the absorption spectra of nanoparticles were $445 \mathrm{~nm}$ after $24 \mathrm{hrs}$. and maximum absorption intensity over time was $450 \mathrm{~nm}$ after $48 \mathrm{hrs}$. while the intensity of absorption of silver nanoparticles synthesized by A. flavus KY609551, whereas the absorption of nanoparticles in case of A. fumigatus MT994683 was $440 \mathrm{~nm}$ and $445 \mathrm{~nm}$, respectively

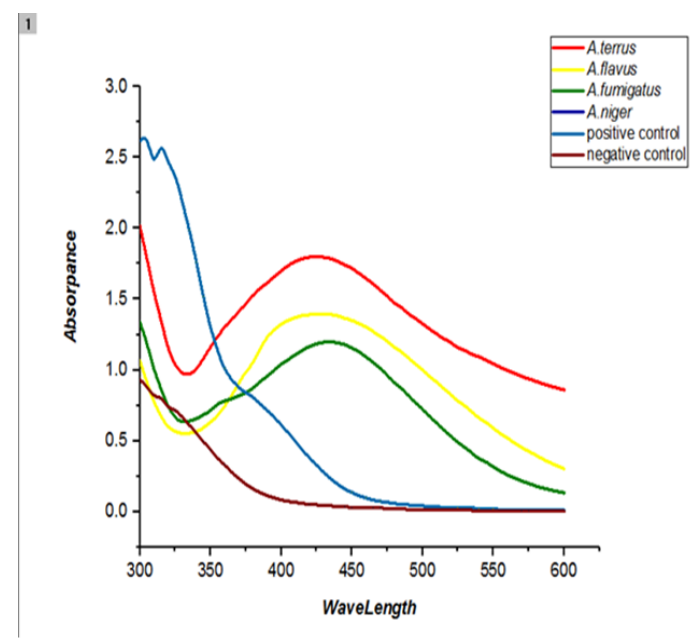

Figure 2 : UV-Vis. spectra of SNPs extract from extracellular enzyme of Aspergillus sp after 24h that A.terreus MF852635 SPR was (450 nm with $\mathrm{OD}=1.6$ ) while A.flavus KY609551 UV-visible absorption spectra of biosynthesized SNPs was $(440 \mathrm{~nm}$ with $\mathrm{OD}=1.2)$ whereas A.fumigatus MT994683 was $(435 \mathrm{~nm}$ with $\mathrm{OD}=1.3)$.

\section{Fourier transforms infrared spectroscopy (FTIR)}

To identify biomolecules responsible for the reduction of the $\mathrm{Ag}^{+}$ions and stabilization (capping) bio-reduced silver nanoparticles synthesized by both fungal species at $37^{\circ} \mathrm{C}$ Aqueous samples are commonly used to detect function groups that may exist and are responsible for nanoparticles synthesis. By using aqueous sample for FTIR analysis, it was found that $(-\mathrm{OH})$ peak at $3306.90 \mathrm{~cm}^{-1}$ covered amines group (-NH) making it difficult to identify the characteristic protein groups responsible for biosynthesis after 24 hrs. (Fig. 3). Our results were matches with Jain et al. (2011) who reported that A. flavus NJP08 the UV-visible spectra of silver nitrate solutions when challenged with A. flavus NJP08, characteristic surface plasmon absorption band of SNPs was observed at $420 \mathrm{~nm}$. Bhainsa \& D'Souza (2006) reported that absorption maxima ( $\lambda \max )$ of biosynthesized SNPs observed in the range of $420 \mathrm{~nm}$ in Aspergillus fumigatus.

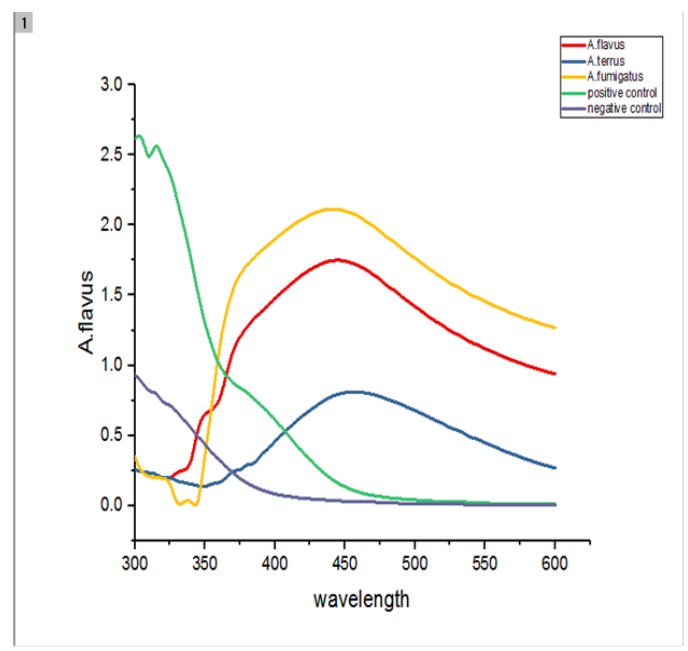

Figure 3: UV-Vis. spectra of SNPs extract from Intracellular enzyme of Aspergillus sp after 24h that A.terreus MF852635 SPR was (445 nm with $\mathrm{OD}=1$ ) while A.flavus KY609551 UV-visible absorption spectra of biosynthesized SNPs was(440nm with $\mathrm{OD}=1.5)$ whereas A.fumigatus MT994683 was ( $445 \mathrm{~nm}$ with $\mathrm{OD}=2)$ as $\mathrm{OD}$ values refer the concentration of silver nanoparticles, which gives a strong indication of the stability of these particles, as the more $\mathrm{OD}$ value greater than 1.5 , the nanoparticles lose their stability.

nanoparticles, one peak at $1636.62 \mathrm{~cm}^{-1}$ refers to amide I (Fig. 4).

A simple modified method to overcome hiding an amides group in case of aqueous solution extract, a simple modified technique was used by extracting SNPs from the aqueous solution using chloroform. The chloroform extract was separated from the aqueous solution containing SNPs, collected by a separated funnel and let them to dry at room temperature Aboul Nasr et al. (2018). FTIR spectrum revealed one peak at $1646 \mathrm{~cm}^{-1}$ that corresponds to the bending vibrations of the amide 
I and amide II bands of the proteins, respectively; while their corresponding stretching vibrations were seen at $2918 \mathrm{~cm}^{-1}$, respectively. While the peaks centered at 3351 and $3300 \mathrm{~cm}^{-1}$ are for N-H (amines group) stretching. It is well known that protein-nanoparticle interactions can occur either through free amine groups or cysteine residues in proteins and via the electrostatic attraction of negatively charged carboxylate groups in enzymes Gole et al. (2001). The peaks centered at 2960, $2871 \mathrm{~cm}^{-1}$ for $\left(\mathrm{CH}_{3}\right.$ mostly protein and lipid) and $2933 \mathrm{~cm}^{-1}$ are for $\left(\mathrm{CH}_{2}\right.$ mostly protein), while the peak in $1733.26 \mathrm{~cm}^{-1}$ is for $\mathrm{C}=\mathrm{O}$ (carboxylic acid) stretching, typical of saccharides. The appearance of peak at 1376.40 and $1022.29 \mathrm{~cm}^{-1}$ can be assigned to the $\mathrm{C}-\mathrm{N}$ stretching vibrations of the aromatic and aliphatic amines (Alkaline amine) (Fig. 5).

These observations indicated that the stability of silver nanoparticles is due to the presence and binding of proteins with silver nanoparticles. FTIR results revealed that the secondary structure of proteins has not been affected as a consequence of reaction with silver ions or binding with silver nanoparticles. It is important to understand, that it is not just the size and shape of proteins, but the conformation of protein molecules that plays an important role (Jain et al. 2011).

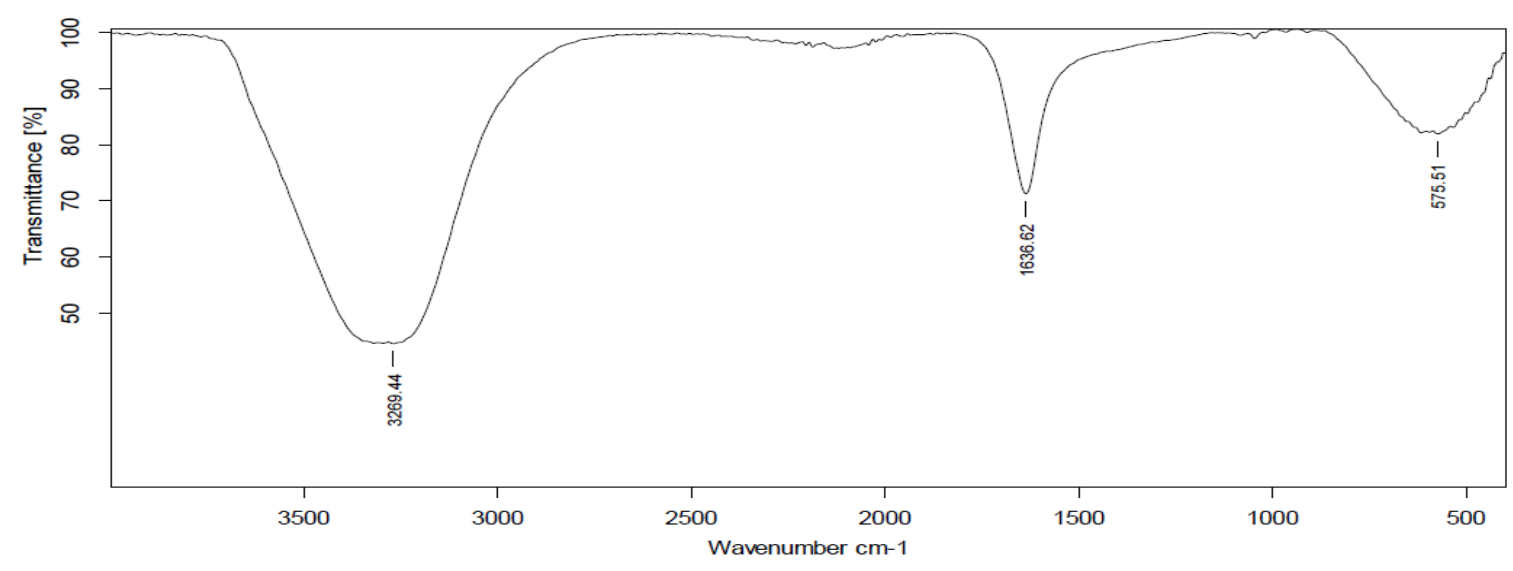

Figure (4) FTIR spectra of aqueous sample of silver nanoparticles at $37^{\circ} \mathrm{C}$

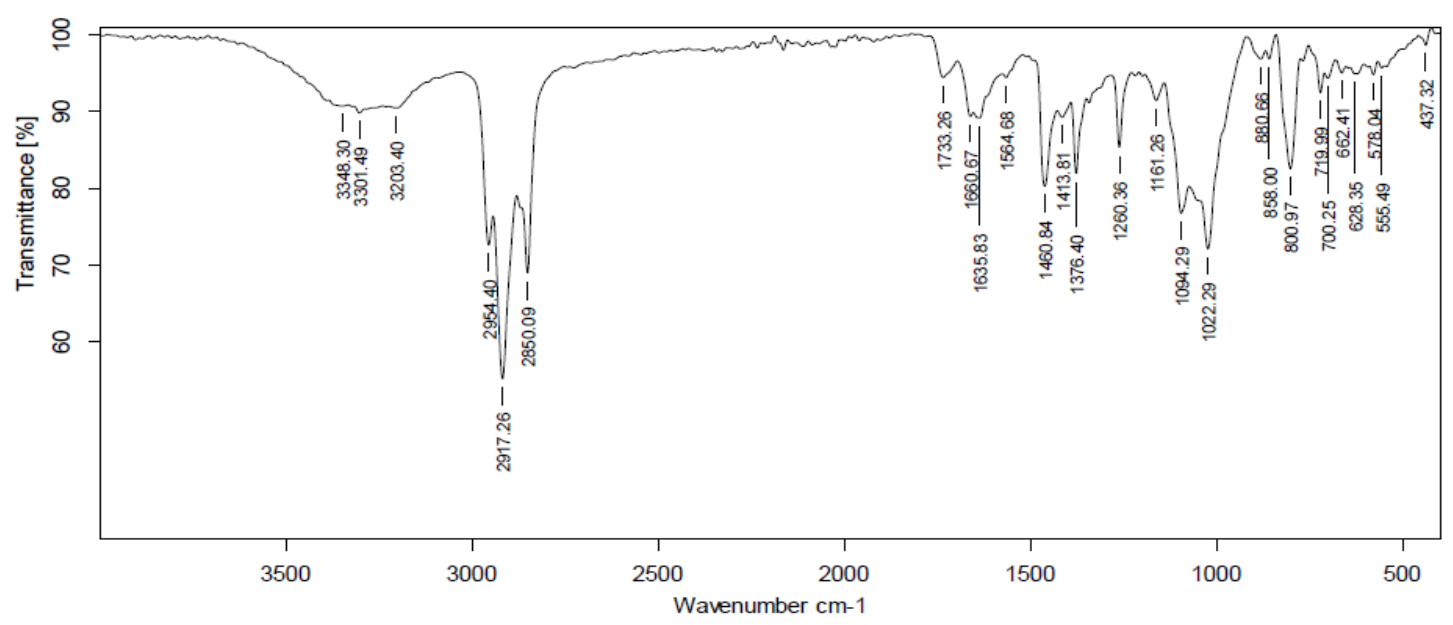

Figure (5) FTIR spectra of dried powder of SNPs extracted with chloroform at $37^{\circ} \mathrm{C}$. 
These results came in coincidence with Fayaz et al. (2010), Jaidev \& Narasimha (2010) who observed that the stable and well dispersion of nanoparticles using FT-IR spectrum showed three distinct peaks, $3347.85,1636.17$ and $548.38 \mathrm{~cm}^{-1}$. The peak at $3347.85 \mathrm{~cm}^{-1}$ indicated to the stretching vibrations of primary amines, while the peak at $1636.17 \mathrm{~cm}^{-1}$ indicated to carbonyl stretch vibrations in the amide linkage of proteins and $548.38 \mathrm{~cm}^{-1}$ is the fingerprint.

\section{X-Ray diffraction}

To prepare the sample in dried form, a simple modified technique was used by extracting SNPs from the aqueous solution using chloroform. The chloroform extract was separated from the aqueous solution containing SNPs collected by separated funnel and let them to dry by air gun Aboul Nasr $\boldsymbol{e t}$ al. (2018).

The XRD pattern shows four intense peaks at $2 \Theta$ values $(38.00,44.28,64.85,77.44)$ corresponding to (111), (200), (220), (311), (222) planes of silver (Fig. 6). Thus, the XRD spectrum confirmed the crystalline structure of silver nanoparticles. These results correlated with Prema \& Rincy (2009) and Narasimha et al. (2011).

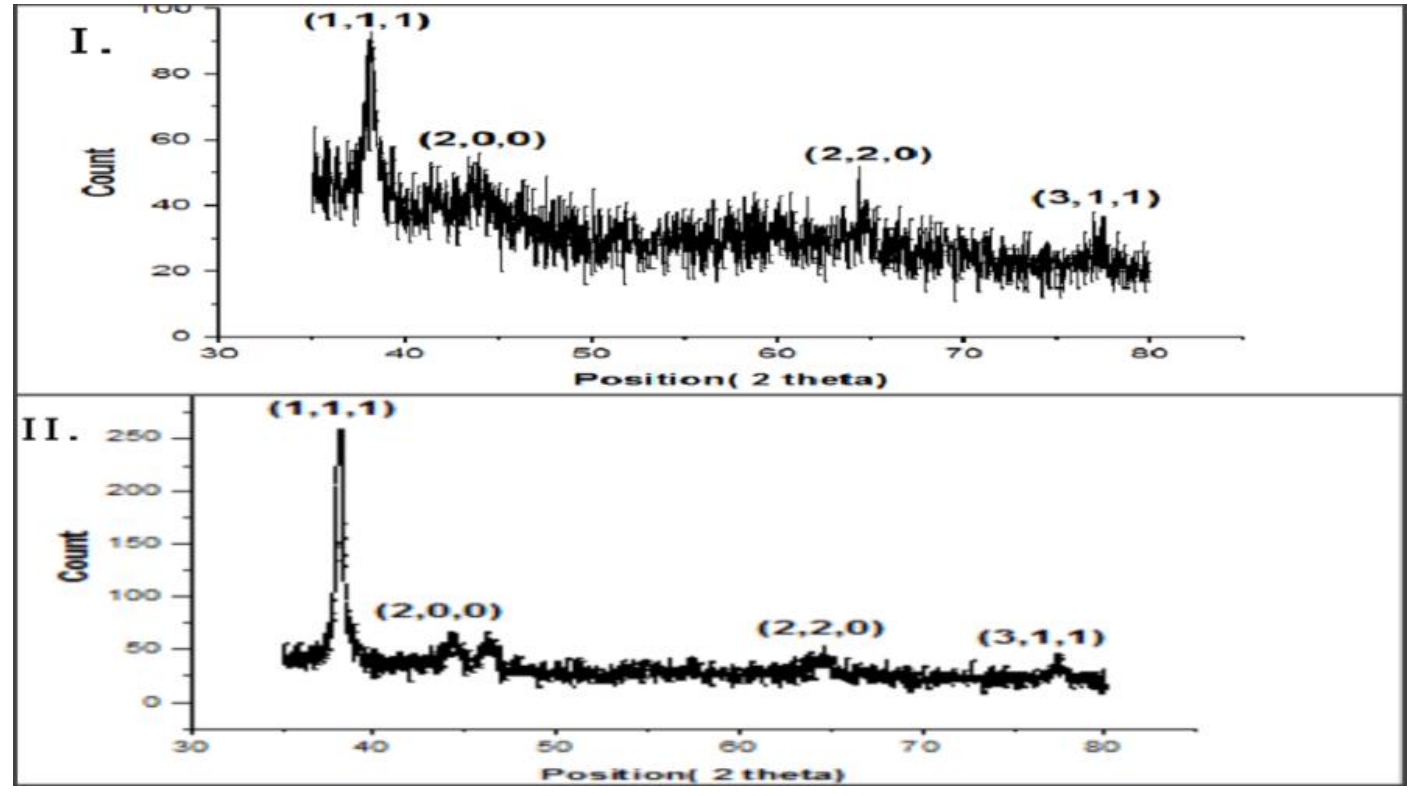

Figure (6). XRD pattern of silver nanoparticles synthesis by I.) A. flavus and II.) A. terreus at $37^{\circ} \mathrm{C}$. An intense peak corresponding to $2 \Theta=38.00$ indicates that the obtained SNPs are dominantly ruled by (111) planes.

\section{CONCLUSION}

In conclusion the enzymatic profile of opportunistic fungi makes them easily mediated SNPs induction extra/intracellularly in case of A. flavus KY609551, A. fumigatus MT994683 and A. terreus MF852635. Whereas A. niger KY609552 produced in high concentration of SNPs. Silver nanoparticles with higher stability was confirmed by using UV-visible spectra, which gives an indication of the constancy of the constituent particles, where SNPs induced by A. flavus KY609551 were more stable followed by A. terreus MF852635 and A. fumigatus MT994683. Extracting of the aqueous solution containing SNPs synthesized by A. flavus KY609551 and A. terreus MF852635 by simple methods modified with chloroform enhanced the results of FTIR by not hiding an amide group in case of using aqueous extract and gave better X-Ray diffraction identification of crystalline nature of the SNPs. The 
chloroform extract was also the first to be used by the author to extract nanoparticles from its aqueous solution, which can be easily dried at room temperature and by an air gun, which gave a better result than the conventional methods.

\section{REFERENCE}

Aboul El-Nour K. M., Eftaiha A. A., Al-Warthan A., Ammar R. A. (2010). Synthesis and applications of silver nanoparticles. Arabian journal of chemistry, 3(3): 135-140.

Aboul Nasr M., Sabah S. M., Alaa A. Y. (2018). Mycogenesis of silver nanoparticles using selected strains of opportunistic fungi and their efficacy against aspergillosis causal agents". Journal of Ecosystem \& Ecography, 2157-7625.

Ahmad A., Mukherjee P., Senapati S., Mandal D., Khan M. I., Kumar R., Sastry M. (2003). Extracellular biosynthesis of silver nanoparticles using the fungus Fusarium oxysporum. Colloids and surfaces B: Biointerfaces, 28(4): 313-318.

Ahmad N., Sharma S., Singh V. N., Shamsi S. F., Fatma A., \& Mehta, B. R. (2011). Biosynthesis of silver nanoparticles from Desmodium triflorum: a novel approach towards weed utilization. Biotechnology Research International.

Alon N., Miroshnikov Y., Perkas N., Nissan I., Gedanken A., Shefi O. (2014). Substrates coated with silver nanoparticles as a neuronal regenerative material. International journal of nanomedicine, 9(Suppl 1): 23.

Arumugam P., Berchmans S. (2011). Synthesis of gold nanoparticles: An ecofriendly approach using Hansenula anomala. ACS applied materials \& interfaces, 3(5), 1418

Balaji D. S., Basavaraja S., Deshpande R., Mahesh D. B., Prabhakar B. K., Venkataraman A. (2009). Extracellular biosynthesis of functionalized silver nanoparticles by strains of Cladosporium cladosporioides fungus. Colloids and surfaces B: biointerfaces, 68(1): 88-92.

Bansal V., Rautaray D., Bharde A., Ahire K., Sanyal A., Ahmad A., Sastry M. (2005). Fungus-mediated biosynthesis of silica and titania particles. Journal of Materials Chemistry, 15(26), 2583-2589.

Bhainsa K. C., D'souza S. F. (2006). Extracellular biosynthesis of silver nanoparticles using the fungus Aspergillus fumigatus. Colloids and surfaces B: Biointerfaces, 47(2): 160-164.

Birla S. S., Gaikwad S. C., Gade A. K., Rai M. K. (2013). Rapid synthesis of silver nanoparticles from Fusarium oxysporum by optimizing physicocultural conditions. The Scientific World Journal.

Colvin V. L., Schlamp M. C., Alivisatos A. (1994). "Light emitting diodes made from cadmium selenide nanocrystals and a semiconducting polymer." Nature, 370: 354357.

El-Aziz A., Abeer R., AL-Othman M. R., Eifan S. A., Mahamed M. A., Majrashi M. (2013). Green synthesis of silver nanoparticles using Aspergillus terreus (KC462061). Digest Journal of Nanomaterials \& Biostructures $8(3)$.

Elumalai E. K., Kayalvizhi K., Silvan S. (2014). Coconut water assisted green synthesis of 
silver nanoparticles. Journal of pharmacy \& bioallied sciences, 6(4): 241.

Enas M. A., Aboul Nasr M. B, Zohri A. A., Adam M. F. (2017). Fungal causal agents of aspergillosis chest disease at Assuit university hospital, Assiut, Egypt and the efficacy of four antifungal compounds in vitro and in vivo. Biomedical Research. 28:1-23.

Evtugyn G. A., Shamagsumova R. V., Padnya P. V., Stoikov I. I., Antipin I. S. (2014). Cholinesterase sensor based on glassy carbon electrode modified with $\mathrm{Ag}$ nanoparticles decorated with macrocyclic ligands. Talanta, 127: 9-17.

Fayaz A. M., Balaji K., Girilal M., Yadav R., Kalaichelvan P. T., Venketesan R. (2010). Biogenic synthesis of silver nanoparticles and their synergistic effect with antibiotics: a study against gram-positive and gram-negative bacteria. Nanomedicine: Nanotechnology, Biology and Medicine, 6(1): 103-109.

Franci G., Falanga A., Galdiero S., Palomba L., Rai M., Morelli G., Galdiero M. (2015). Silver nanoparticles as potential antibacterial agents. Molecules, 20(5): 8856-8874.

Gade A. K., Bonde P. P., Ingle A. P., Marcato P. D., Duran N., Rai M. K. (2008). Exploitation of Aspergillus niger for synthesis of silver nanoparticles. Journal of Biobased Materials and Bioenergy, 2(3): 243-247.

Gole A., Dash C., Ramakrishnan V., Sainkar S.R., Mandale A. B., Rao M., Sastry M. (2001). Pepsin-gold colloid conjugates: preparation, characterization, and enzymatic activity. Langmuir, 17(5): 1674-1679.
Ingle A., Rai M., Gade A., Bawaskar, M. (2009). Fusarium solani: a novel biological agent for the extracellular synthesis of silver nanoparticles. Journal of Nanoparticle Research, 11(8): 2079.

Jaidev L. R., Narasimha G. (2010). Fungal mediated biosynthesis of silver nanoparticles, characterization, and antimicrobial activity. Colloids and surfaces B: Biointerfaces, 81(2): 430-433.

Jain N., Bhargava A., Majumdar S., Tarafdar J. C., Panwar J. (2011). Extracellular biosynthesis and characterization of silver nanoparticles using Aspergillus flavus NJP08: a mechanism perspective. Nanoscale, 3(2): 635-641.

Jha A. K., Prasad K., Prasad K. (2009). A green low-cost biosynthesis of $\mathrm{Sb}_{2} \mathrm{O}_{3}$ nanoparticles. Biochemical engineering journal, 43(3): 303306.

Jha A. K., Prasad K., Prasad K., Kulkarni A. R. (2009). Plant system: nature's nanofactory. Colloids and Surfaces B: Biointerfaces, 73(2): 219-223.

Kalathil S., Lee J., Cho M. H. (2013). Gold nanoparticles produced in situ mediate bioelectricity and hydrogen production in a microbial fuel cell by quantized capacitance charging. ChemSusChem, 6(2): 246-250.

Kowshik M., Vogel W., Urban J., Kulkarni S. K., Paknikar K. M. (2002). Microbial synthesis of semiconductor PbS nanocrystallites. Advanced Materials, 14(11): 815-818.

Li G., He D., Qian Y., Guan B., Gao S., Cui Y., Yokoyama K., Wang L. (2012). Fungusmediated green synthesis of silver nanoparticles using Aspergillus terreus. 
International journal of molecular science, 13(1): 466-476.

Mansoori G. A. (2005). Principles of Nanotechnology- Molecular-Based Study of Condensed Matter in Small Systems, World Scientific Pub. Co., Hackensack, NJ. Available from: http//tigger.uic.edu.

[Accessed on 12th February 2017]

Meyer V. (2008). Genetic engineering of filamentous fungi - progress, obstacles and future trends. Biotechnology advances, 26(2): 177-185.

Mohanpuria P., Rana N. K., Yadav S. K. (2008). Biosynthesis of nanoparticles: technological concepts and future applications. Journal of nanoparticle research, 10(3): 507-517.

Mukherjee P., Ahmad A., Mandal D., Senapati S., Sainkar S. R., Khan M. I., Parishcha R., Ajaykumar P. V., Alam M., Kumar R., Sastry M. (2001). Fungus-mediated synthesis of silver nanoparticles and their immobilization in the mycelial matrix: a novel biological approach to nanoparticle synthesis. Nano letters, 1(10): 515-519.

Nanda A., Saravanan M. (2009). Biosynthesis of silver nanoparticles from Staphylococcus aureus and its antimicrobial activity against MRSA and MRSE. Nanomedicine: Nanotechnology, Biology and Medicine, 5(4): 452-456.

Narasimha G, Janardhan A, Alzohairy M, Khadri H, Mallikarjuna K. (2013) Extracellular synthesis, characterization and antibacterial activity of silver nanoparticles by actinomycetes isolative. International Journal of Nano Dimensions, 4: 77-83
Narasimha G., Praveen B., Mallikarjuna K., Deva P. R. B. (2011). Mushrooms (Agaricus bisporus) mediated biosynthesis of sliver nanoparticles, characterization and their antimicrobial activity.

Narayanan K. B., Sakthivel N. (2010). Biological synthesis of metal nanoparticles by microbes. Advances in colloid and interface science, 156(1-2): 1-13.

Prema P., Rincy R. (2009). Fabrication and characterization of silver nanoparticle and its potential antibacterial activity. Biotechnology and Bioprocess Engineering, 14(6): 842-847.

Rao P., Chandraprasad M. S., Lakshmi Y. N., Rao J., Aishwarya P., Shetty S. (2014). Biosynthesis of silver nanoparticles using lemon extract and its antibacterial activity. International Journal of Multidisciplinary and Current Research, 2: 165-169.

Sagar G., Ashok B. (2012). Green synthesis of silver nanoparticles using Aspergillus niger and its efficacy against human pathogens. European Journal of Experimental Biology, 2(5): 1654-1658.

Saifuddin N., Wong C. W., Yasumira A. A. (2009). Rapid biosynthesis of silver nanoparticles using culture supernatant of bacteria with microwave irradiation. Journal of Chemistry, 6(1): 61-70.

Sastry M., Ahmad A., Khan M. I., Kumar R. (2003). Biosynthesis of metal nanoparticles using fungi and actinomycete. Current science, 85(2): 162-170.

Shankar S. S., Ahmad A., Sastry M. (2003). Geranium leaf assisted biosynthesis of silver 
nanoparticles. Biotechnology progress, 19(6): 1627-1631.

Shankar S. S., Rai A., Ankamwar B., Singh A., Ahmad A., Sastry M. (2004). Biological synthesis of triangular gold nanoprisms. Nature materials, 3(7): 482-488.

Sintubin L., De Windt W., Dick J., Mast J., Van Der Ha D., Verstraete W., Boon N. (2009). Lactic acid bacteria as reducing and capping agent for the fast and efficient production of silver nanoparticles. Applied Microbiology and Biotechnology, 84(4): 741-749.

Stiufiuc R., Iacovita C., Lucaciu C. M., Stiufiuc G., Dutu A. G., Braescu C., Leopold N. (2013). SERS-active silver colloids prepared by reduction of silver nitrate with short-chain polyethylene glycol. Nanoscale research letter, 8(1): 47.
Verma V. C., Kharwar R. N., Gange A. C. (2010). Biosynthesis of antimicrobial silver nanoparticles by the endophytic fungus Aspergillus clavatus. Nanomedicine, 5(1): 3340.

Vigneshwaran N., Ashtaputre N. M., Varadarajan P. V., Nachane R. P., Paralikar K. M., Balasubramanya R. H. (2007). Biological synthesis of silver nanoparticles using the fungus Aspergillus flavus. Materials letters, 61(6): 1413-1418.

Vigneshwaran N., Kathe A. A., Varadarajan P. V., Nachane R. P., Balasubramanya R. H. (2006). Biomimetics of silver nanoparticles by white rot fungus, Phaenerochaete chryosporium. Colloids and Surfaces B: Biointerfaces, 53(1): 55-59. 